\title{
Inflammation and breast cancer
}

\author{
Li-Pin Kao ${ }^{1,2 *}$ \\ ${ }^{1}$ Department of Basic Medical Sciences, Purdue University, West Lafayette, Indiana, USA \\ ${ }^{2}$ Centre for Cancer Research, Purdue University, West Lafayette, Indiana, USA
}

\begin{abstract}
Chronic inflammation is a critical factor in tumor progression. Adipocyte accumulation and cytokines storm during inflammation have a significant impact on breast cancer. The development of cancer arises from sites of infection, chronic irritation and inflammation. Furthermore, tumor seed in tumor microenvironment as seed and soil, orchestrated by inflammatory cells, is an indispensable for cells transformed into benign or malignancy status and further fostering proliferation, survival, and migration. These insights are fostering new anti-inflammatory therapeutic approaches to cancer development.
\end{abstract}

\section{Introduction}

Breast cancer (BC), the first most common malignant tumor in women worldwide (Figure 1) [1]. Many etiological factors such as a wide spectrum of clinical manifestations caused by family clustering, hormonal factors, lactation, early menarche, metabolic and secretory factors, obesity, dietary factors, alcohol consumption, smoking, and lose-dose irradiation [2]. On top of that, obesity, alcoholism, and tobacco smoking were found to result in this incidence [3-6]. Many of the established risk factors are linked to estrogens. Risk is increased by early menarche, late menopause, and obesity in postmenopausal women, and prospective studies have shown that high concentrations of endogenous estradiol are associated with an increase in risk [7]. Childbearing reduces risk, with greater protection for early first birth and a larger number of births; breastfeeding probably has a protective effect. Both oral contraceptives and hormonal therapy for menopause cause a small increase in breast-cancer risk, which appears to diminish once use stops. Alcohol increases risk, whereas physical activity has been suggested as protective. Mutations in certain genes greatly increase breast cancer risk, but these account for a minority of cases. The natural therapeutic (i.e. nutritional supplements) are still discovering in progress to prevent the unnecessary aggressive procedures, although there are many FDA-approval drugs for breast cancers $[8,9]$. Tumors are heterogenous and individual has inherited different genetic background. Thus, it is hard to find an effective treatment and it may recurrent after recovery from first treatment.

\section{Obesity accelerate the worse the breast cancer}

The proportion of obesity has been distributed various within United State (Figure 2). Obesity is known as a key contributory factor associated with cancer risk and mortality. Obesity has resulted increase cells accumulated lipids and slowly differentiated into mature adipocytes. Study also demonstrated that adipocytes are released chemokines to attract eosinophils and monocytes which release cytokine (interleukin-4, 5, -13, and TNFa) which resulted in helminth immunity, activated macrophages associated with glucose homeostasis [10]. Moreover, other study had demonstrated that adipocyte-associated lung neutrophilia and subsequent exacerbate the stimulatory effects of a primary tumor on neutrophils and further enhanced metastatic seeding [11]. Obesity produces an inflammatory state, characterized by macrophages clustered around enlarged hypertrophied, dead, and dying adipocytes from crown-like structures. There are two different type of adipocyte (white or brown). They have different metabolic demands. Due to adipocyte size and taken over the reasonable space, tissues may damage and slow recovery due to chronic inflammation damage which potentially decreases cell proliferation and increases tissue damage. This abnormal condition results in an increase in fibrous tissue and further leads to the development of cancer [12]. Adipocytes has been suggesting as a major factor in provide as seed and soil to manipulate the microenvironments, may differentiated the normal cells toward to malignancy status (Figure 3). Thus, adipocytes may contribute significant to inflammation, immunity, extracellular matrix mechanics, epigenetic or transcriptional regulation, and protein translation in cancers.

Moreover, inflammatory breast cancer (IBC) is a rare, but aggressive type of locally advanced breast cancer. The great portion of IBC cases are also triple negative (TN) patients. The signs of IBC often appear faster than other type of BC, such as redness and swelling which often first treated with antibiotics. Due to the lack of breast lump and symptoms, IBC often misdiagnosis or miss the best treatment time frame. Most of patients with IBC have advanced-stage disease by the time they begin treatment. The inflammation recruits immune cells which release the cytokines and chemokines which provide seed and soil microenvironment to facilitate metastasis such as Epithelial-toMesenchymal transition (EMT) [13-15].

Thus, it is it important to increase our understanding of how IBC can be better diagnosed and how biology drives its progression which can leads to improve diagnosis, prognosis with more effective treatment for those with this aggressive disease.

Correspondence to: Li-Pin Kao, Department of Basic Medical Sciences, Purdue University and Centre for Cancer Research, Purdue University, West Lafayette, Indiana, USA, Tel: 1-480-386-3443; E-mail: kaolipin@gmail.com

Key words: breast cancer, inflammation, obesity

Received: January 19, 2018; Accepted: February 14, 2018; Published: February 17,2018 


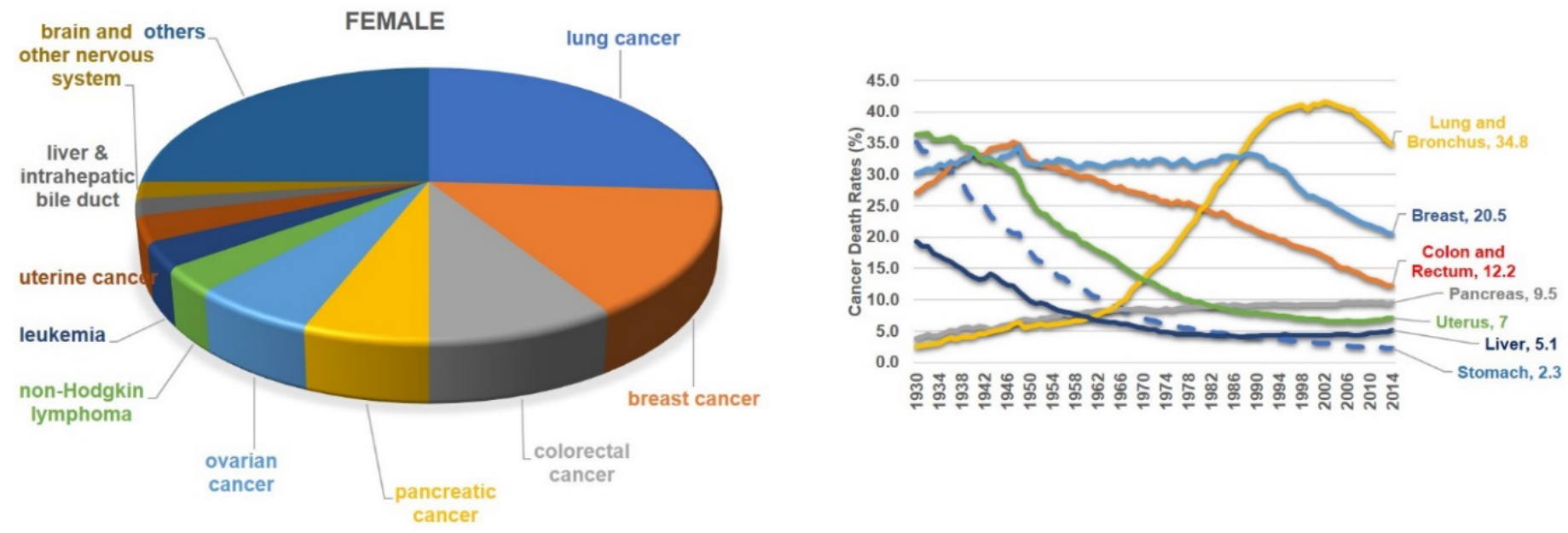

Figure 1. The overview of the proportional of different type of cancers in female.
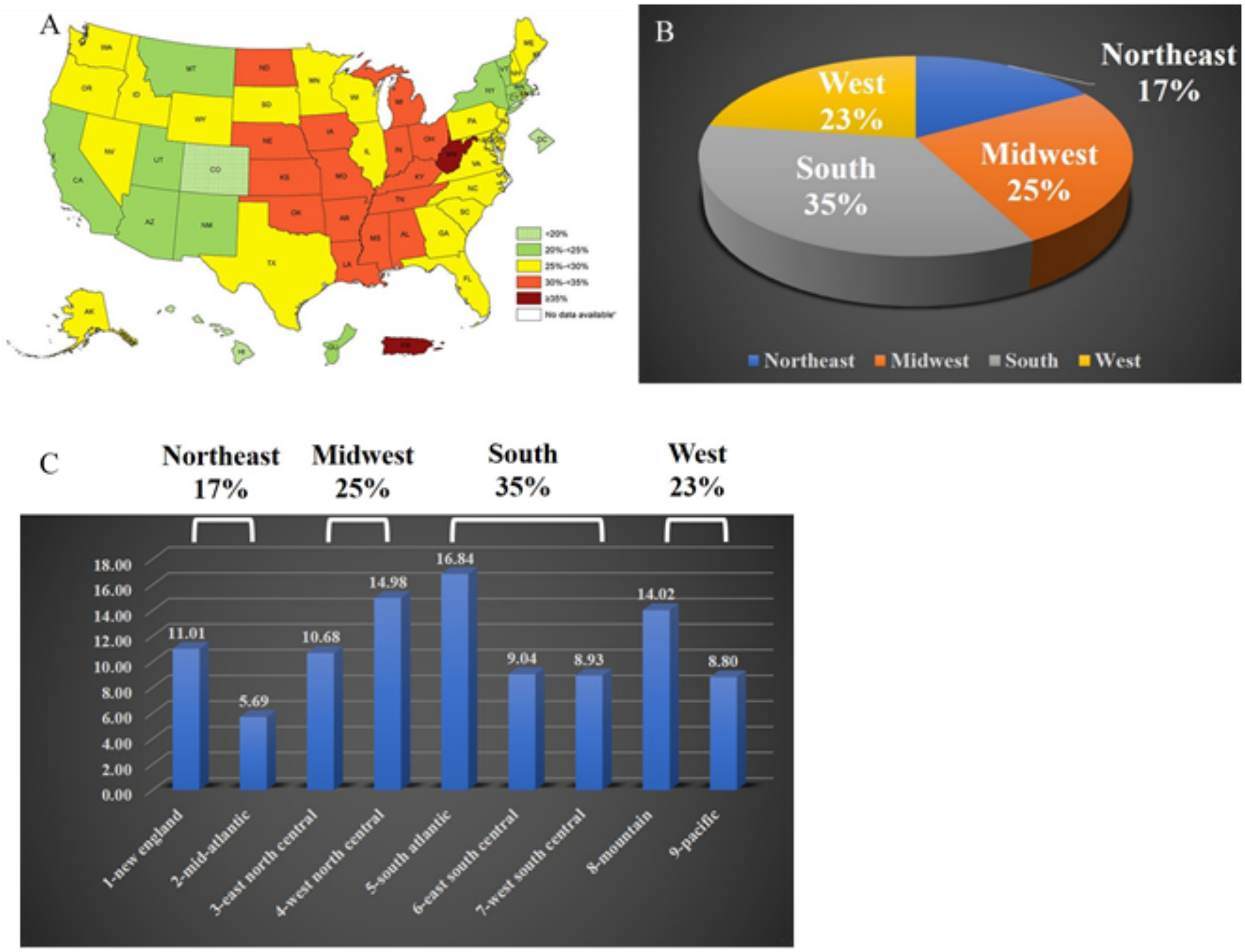

Figure 2. Distribution of obesity within United State. (A) Adult obesity prevalence maps. Prevalence of self-reported obesity among non-Hispanic white adults by state and Territory. (B) Pie chart of 4 main regions. (C) Bar graph of the proportion of obesity within each region. (https://www.cdc.gov/obesity/data/prevalence-maps.html \& https://www.cancer.gov/about-cancer/ causes-prevention/risk/obesity/obesity-fact-sheet) 


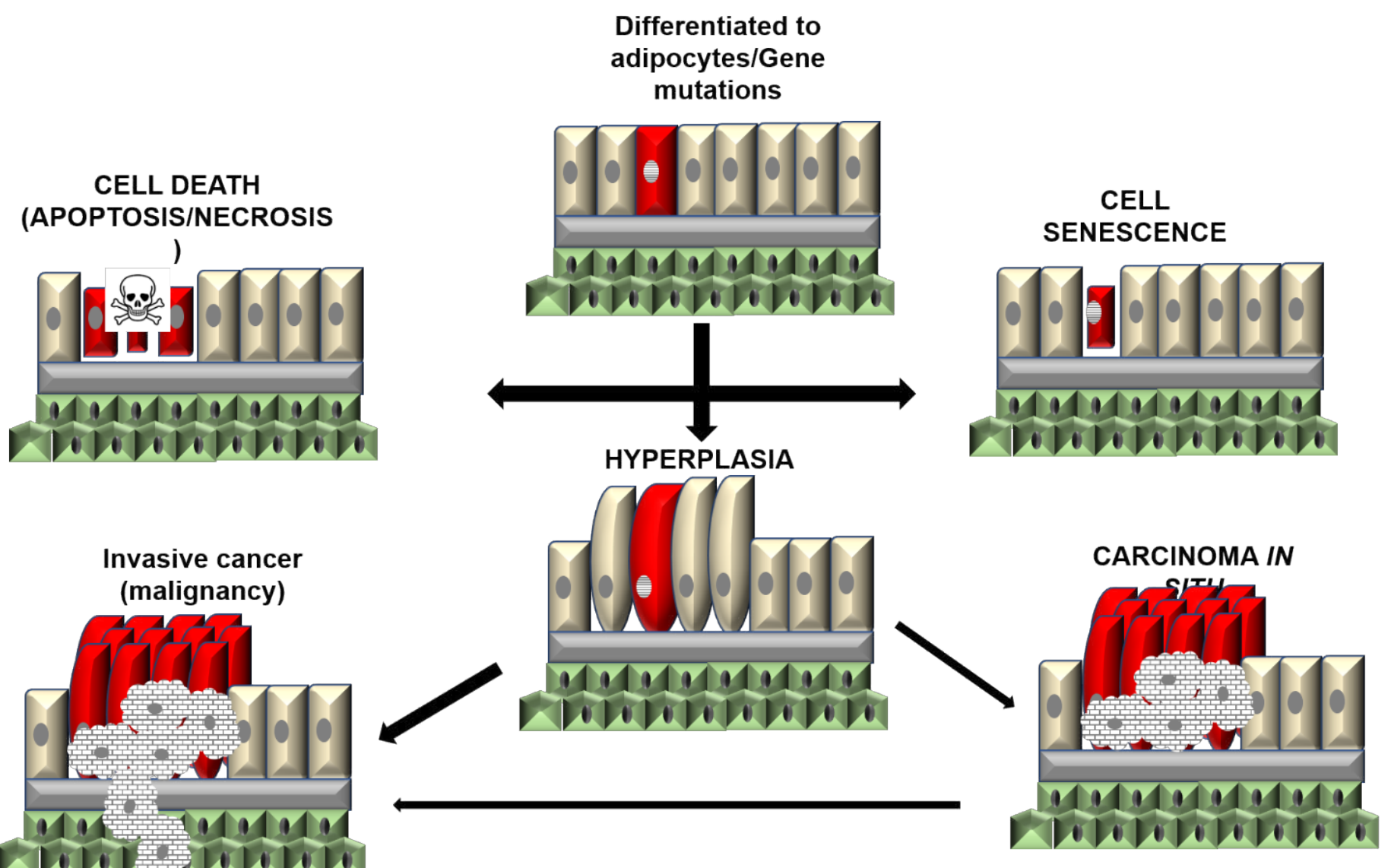

Figure 3. The process of cellular transformation into malignancy

\section{Disclosure of potential conflicts of interest}

The author indicates no potential conflict of interest

\section{Acknowledgement}

The author would like to acknowledge the financial support of the Purdue University for provided support in the form of salaries of KLP listed but did not have any additional role in the study design, data collection and analysis, decision to publish, or preparation of the manuscript.

\section{References}

1. Siegel RL, Miller KD, Jemal A (2017) Cancer Statistics. CA Cancer J Clin 67: 7-30. [Crossref]

2. Key TJ, Reeves GK (2016) Alcohol, diet, and risk of breast cancer. BMJ 353: i2503. [Crossref]

3. Kerr J, Anderson C, Lippman SM (2017) Physical activity, sedentary behaviour, diet, and cancer: an update and emerging new evidence. Lancet Oncol 18: 457-e471. [Crossref]

4. Macacu A, Autier P, Boniol M, Boyle P (2015) Active and passive smoking and risk of breast cancer: a meta-analysis. Breast Cancer Res Treat 154: 213-224. [Crossref]

5. Calle EE, Rodriguez C, Walker-Thurmond K, Thun MJ (2003) Overweight, obesity, and mortality from cancer in a prospectively studied cohort of U.S. adults. $N$ Engl $J$ Med 348: 1625-1638. [Crossref]

6. Key TJ, Schatzkin A, Willett WC, Allen NE, Spencer EA, et al. (2004) Diet, nutrition and the prevention of cancer. Public Health Nutr 7: 187-200. [Crossref]

7. Key TJ, Allen NE, Spencer EA, Travis RC (2002) The effect of diet on risk of cancer. Lancet 360: 861-868. [Crossref]
8. Shui IM, Mondul AM, Lindström S, Tsilidis KK, Travis RC, et al. (2015) Circulating vitamin $\mathrm{D}$, vitamin D-related genetic variation, and risk of fatal prostate cancer in the National Cancer Institute Breast and Prostate Cancer Cohort Consortium. Cancer 121: 1949-1956. [Crossref]

9. Bakker MF, Peeters PH, Klaasen VM, Bueno-de-Mesquita HB4, Jansen EH5, et al (2016) Plasma carotenoids, vitamin C, tocopherols, and retinol and the risk of breast cancer in the European Prospective Investigation into Cancer and Nutrition cohort. Am J Clin Nutr 103: 454-464. [Crossref]

10. Wu D, Molofsky AB, Liang HE, Ricardo-Gonzalez RR, Jouihan HA, et al. (2011) Eosinophils sustain adipose alternatively activated macrophages associated with glucose homeostasis. Science 332: 243-247. [Crossref]

11. Quail DF, Olson OC, Bhardwaj P, Walsh LA, Akkari L, et al. (2017) Obesity alters the lung myeloid cell landscape to enhance breast cancer metastasis through IL5 and GMCSF. Nat Cell Biol 19: 974-987. [Crossref]

12. Sanyal AJ, Yoon SK, Lencioni R (2010) The etiology of hepatocellular carcinoma and consequences for treatment. Oncologist 15 Suppl 4: 14-22. [Crossref]

13. Jolly MK, Boareto M2, Debeb BG3, Aceto N4, Farach-Carson MC1, et al. (2017) Inflammatory breast cancer: a model for investigating cluster-based dissemination. NPJ Breast Cancer 3: 21. [Crossref]

14. DeNardo DG, Coussens LM (2007) Inflammation and breast cancer. Balancing immune response: crosstalk between adaptive and innate immune cells during breast cancer progression. Breast Cancer Res 9: 212. [Crossref]

15. Morrow RJ, Etemadi N, Yeo B, Ernst M (2017) Challenging a Misnomer? The Role of Inflammatory Pathways in Inflammatory Breast Cancer. Mediators Inflamm 2017: 4754827. [Crossref]

Copyright: (C2018 Kao LP. This is an open-access article distributed under the terms of the Creative Commons Attribution License, which permits unrestricted use, distribution, and reproduction in any medium, provided the original author and source are credited. 